\title{
Shoulder Reconstruction with Massive Scapular-Proximal Humerus Osteoarticular Allograft after Total Scapulectomy for Proximal Humerus Osteosarcoma Recurrence
}

\author{
Alidou Traoré1, Karim Tribak², Brahima Doukouré3, Daouda Kanaté Soumaro1, \\ Slim Alban Mbende ${ }^{4}$, Sidi Yaya Traoré1, Rebecca Eva Boka ${ }^{1}$, Christian Delloye ${ }^{2}$ \\ ${ }^{1}$ Trauma and Orthopaedic Unit, Yopougon Teaching Hospital, Abidjan, Cote d'Ivoire \\ ${ }^{2}$ St-Luc University Clinics (UCL), Brussels, Belgium \\ ${ }^{3}$ Department of Pathology, Cocody Teaching Hospital, Abidjan, Cote d'Ivoire \\ ${ }^{4}$ Neurosurgery Unit, Yopougon Teaching Hospital, Abidjan, Cote d'Ivoire \\ Email: tralidou@yahoo.fr
}

Received 8 November 2015; accepted 15 December 2015; published 18 December 2015

Copyright (C) 2015 by authors and Scientific Research Publishing Inc.

This work is licensed under the Creative Commons Attribution International License (CC BY). http://creativecommons.org/licenses/by/4.0/

c. (i) Open Access

\begin{abstract}
Bone tumors are infrequent within the scapula. Total scapulectomy with massive allograft reconstruction represents an attractive alternative to amputation when the whole scapula is invaded with tumor and the neurovascular bundle can be preserved during tumor resection. We report a case of resection of the scapula and proximal humerus for recurrent osteosarcoma with massive allograft reconstruction of the scapula and proximal humerus. A 22-year-old male patient was seen in February 1992 for a pathological fracture of the proximal left humerus. In July 1992, a resection of the proximal end of the humerus followed by a reconstruction with osteochondral allograft and nail osteosynthesis was performed. The postoperative course was uneventful. In September 2009, 17 years later, the patient presented with a huge tumor developed at the level of the scapula. There was no vascular or neurological symptom. Plain radiography showed an expansive osteolytic mass. CT scan demonstrated scapular and proximal humerus invasion. An extended assessment revealed the presence of two pulmonary nodules. The biopsy confirmed the recurrence of osteosarcoma. The indication of a resection of both the left scapula and the 1992 allograft which was completely invaded at its proximal portion and the complete reconstruction of the scapula and the proximal humerus with allograft was made. One year postoperatively, we note a favourable outcome in terms of musculoskeletal functions. Despite two resection surgeries of pulmonary
\end{abstract}


nodules and chemotherapy treatments, the patient developed new lung metastases and an unfavourable outcome. Although shoulder function was almost completely eliminated following surgery, preservation of elbow, wrist and finger motion resulted in an acceptable level of postoperative limb function. This reconstruction appears to be an attractive technique to be used in similar cases. The necessity of a reliable tissue bank with quality allografts in sufficient number is paramount.

\section{Keywords}

Osteosarcoma, Scapula, Proximal Humerus, Allograft

\section{Introduction}

Proximal humerus is the first location of primary tumors of the upper limb and the fourth for all primary malignancies [1] [2]. Their management must meet three requirements: tumor resection, bone defect reconstruction and soft-tissue reconstruction to cover skeletal reconstruction [3]-[5].

Amputation was the usual treatment in the past but its use had been greatly reduced due to in-depth preoperative assessment using cutting-edge imaging modalities, the effectiveness of adjuvant chemotherapy and the progress of surgical reconstruction techniques [2] [3]. The aim of all shoulder girdle reconstruction is to achieve a stable shoulder and to preserve the function of the elbow and the hand [3]-[5].

Reconstruction techniques of the proximal humerus sarcoma are well known [5]-[9]. Scapula sarcoma reconstruction is highly complex surgical procedure and requires careful dissection due to its relationship with neurovascular structures such as brachial plexus and axillary blood vessels. Moreover, several muscles must be retained in order to reconstruct and restore the function and stability of the scapula [10] [11]. There are few reconstruction techniques available in surgical practice. There are few or not all megaprosthesis to reconstruct both the proximal humerus and the scapula [12] [13]. We report a case of resection of the scapula and proximal humerus for recurrent osteosarcoma with massive allograft reconstruction of the scapula and proximal humerus.

\section{Observation}

A 22-year-old male patient was seen in February 1992 for a pathological fracture of the proximal left humerus. The biopsy found a low grade osteosarcoma. Full body CT scanning did not reveal other locations and scintigraphy excluded the presence of metastasis. Magnetic resonance imaging made before and after chemotherapy showed a relatively poor response to chemotherapy. In July 1992 a resection of the proximal end of the humerus followed by a reconstruction with osteochondral allograft and nail osteosynthesis was performed. The postoperative course was uneventful.

In September 2009, 17 years later, as part of a study on the reconstruction of the proximal humerus with osteochondral allograft, the patient presented with a huge tumor developed at the level of the scapula. This mass significantly increased in size in the last six months (Figure 1). The massive football sized tumor was centered on the scapula and occupying the supraspinous fossa subscapularis and subspinous. There was no vascular or neurological symptom. Plain radiography showed an expansive osteolytic mass (Figure 2). CT scan demonstrated scapular and proximal humerus invasion (Figure 3). An extended assessment revealed the presence of two pulmonary nodules. The biopsy confirmed the recurrence of osteosarcoma (Figure 4). The indication of a resection of both the left scapula and the 1992 allograft which is completely invaded at its proximal portion and the complete reconstruction of the scapula and the proximal humerus with allograft was made (Figure 5). A portion of the trapezius, deltoid, rhomboids, the angular and latissimus dorsi was sacrificed. Neurovascular structures were fully respected. The tumor was totally resected (Figure 6). The proximal humerus was reconstructed with a 4.5 LCP plate and then fixated to the teres major, the serratus anterior and rhomboid (Figure 7). The immediate postoperative radiograph showed good bone fixation (Figure 8). One year postoperatively, we note a favourable outcome in terms of musculoskeletal functions with a $30^{\circ}$ abduction (Figure 9), an internal rotation allowing moving the left hand to D10 (Figure 10), normal flexion/extension of the elbow and the wrist (Figure 11). One year control X-ray showed good bone solidification (Figure 12). Passively, the glenohumeral 
is $45^{\circ}$ free and external elbow rotation is $10^{\circ}$. Despite two resection surgeries of pulmonary nodules and chemotherapy treatments, the patient developed new lung metastases and an unfavourable outcome.

Ethical consideration: Informed consent was obtained from a patient. Agreement was obtained from the local ethical committee of the institution (registration number NCT02355301; 2015/26JAN/025).

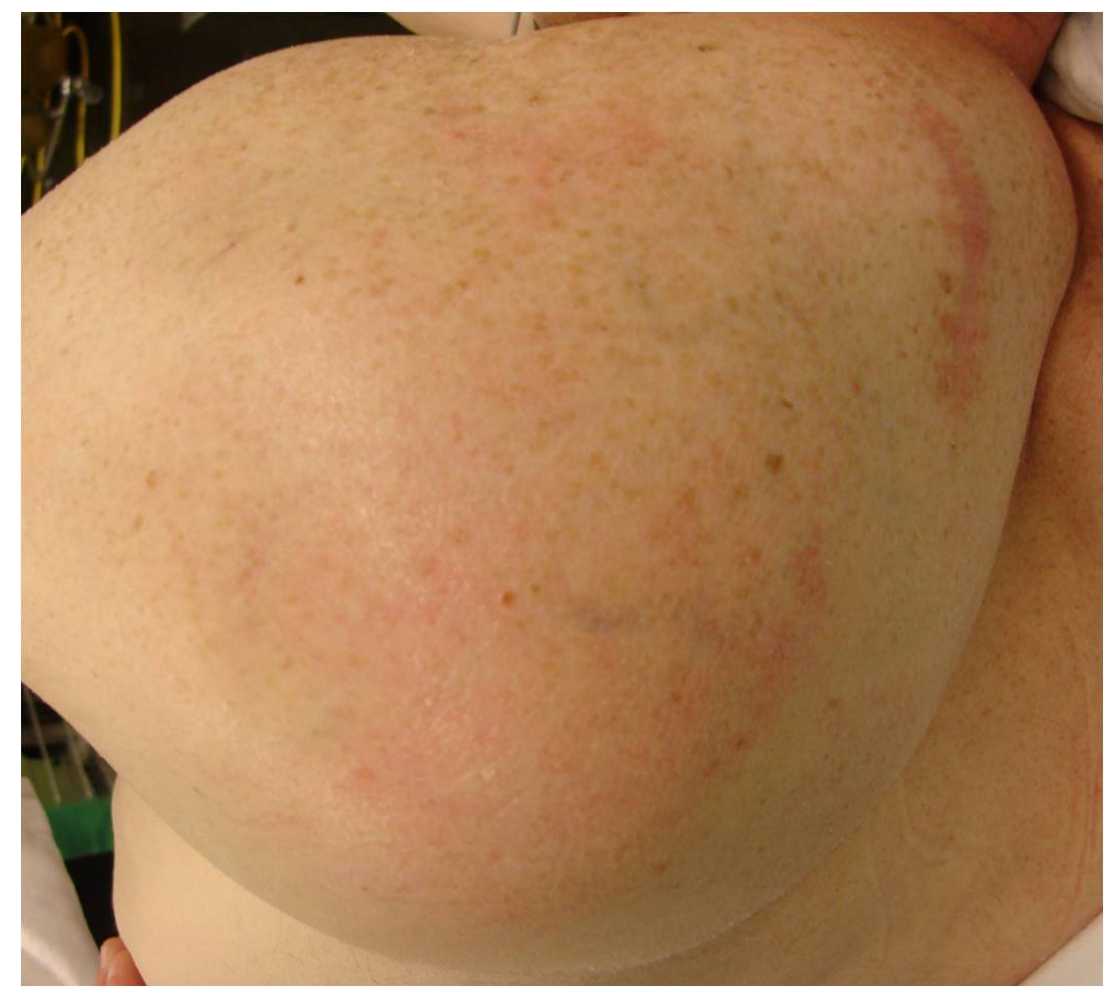

Figure 1. Preoperative aspect of the tumor before reconstruction. Posteriorly, we can see the biopsy scar.

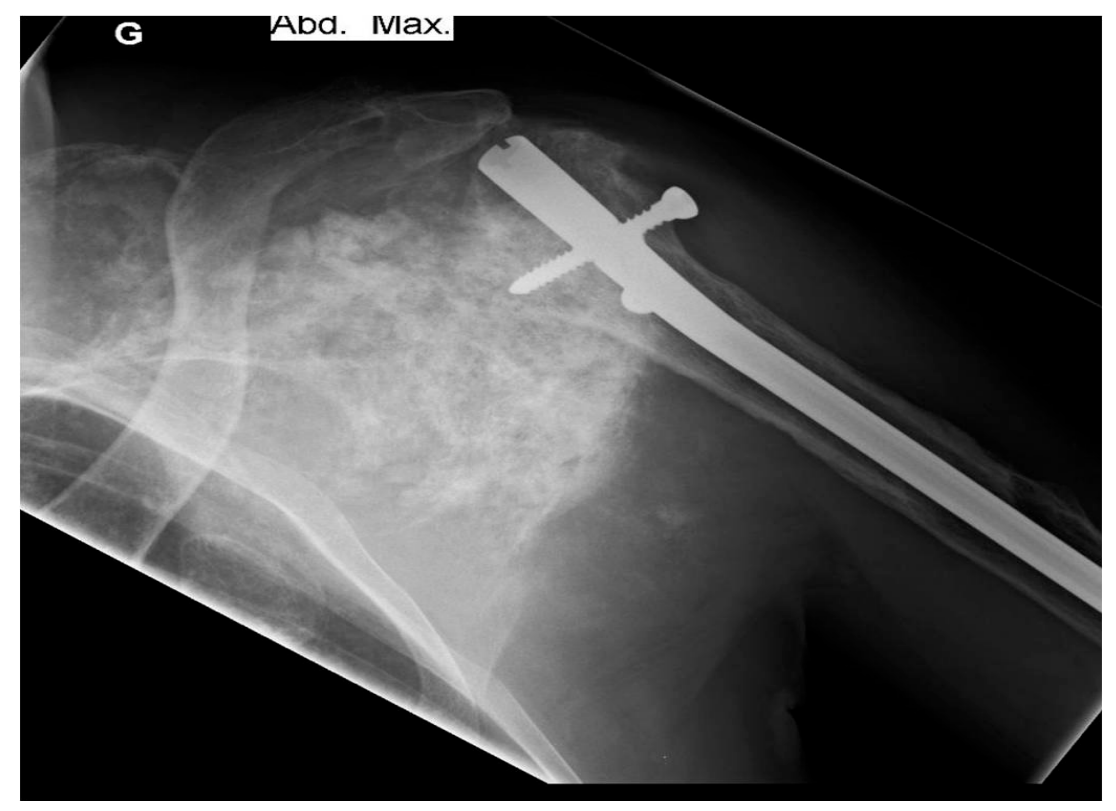

Figure 2. Radiologic aspect of the tumor with recurrence on the 1992 allograft and a scapular invasion. 


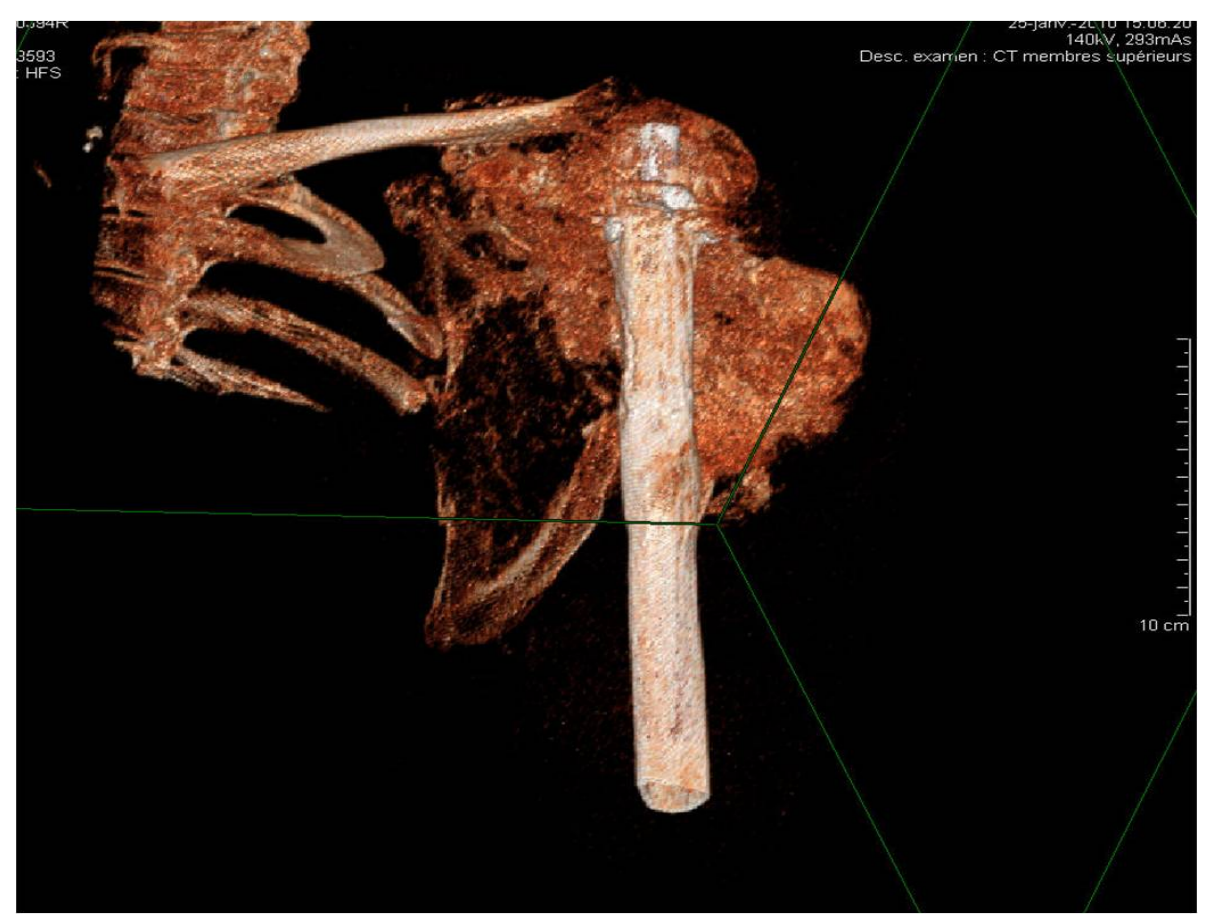

Figure 3. CT scan view of scapula and proximal humerus invasion.

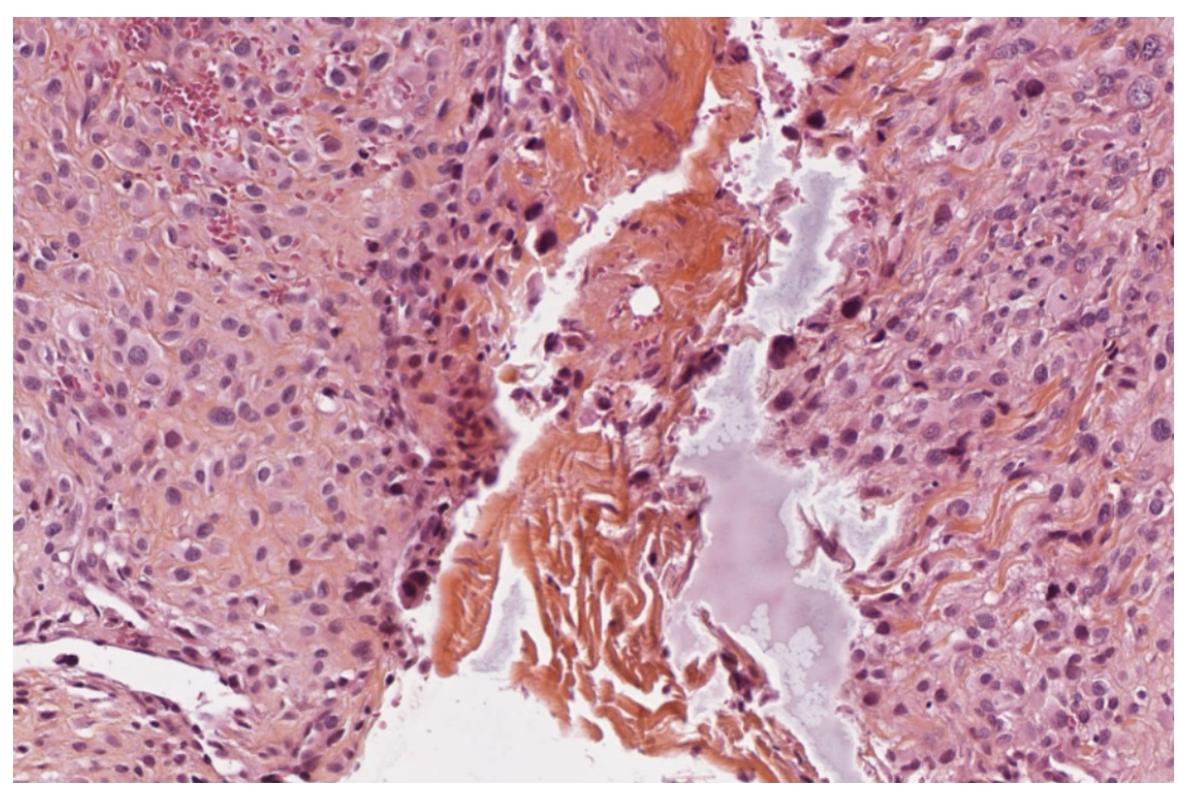

Figure 4. Biopsy demonstrates a proliferation of spindle or polygonal cells developing lamellar bone or osteoid with numerous atypia and mitotic activity $(\mathrm{HE} \times 100)$.

\section{Discussion}

The proximal humerus is a common site for primary malignant bone tumors. Limb-spearing surgery is currently the rule. Technically, resection is difficult due to the proximity of the brachial plexus and axillary vessels [2] [3] [5] [8] [9].

The functional result of conservative treatment of tumors of the shoulder girdle depends on the preservation of the glenoid, the deltoid muscle and tendons of the rotator cuff and neurovascular structures [10]. When proximal humerus or scapula is invaded in isolation, Malawer [5] described several reconstruction techniques 


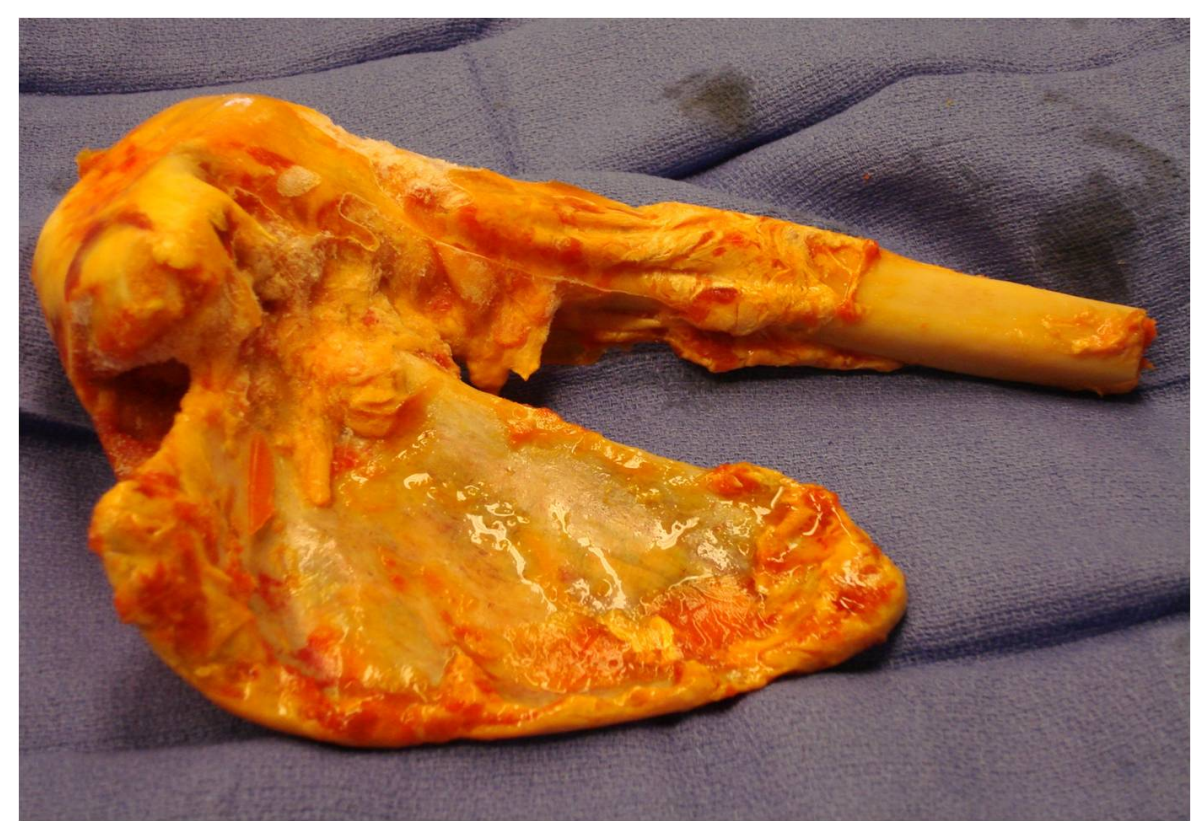

Figure 5. Frozen allograft before being thawed in a physiologic solution mixed with rifampicin.

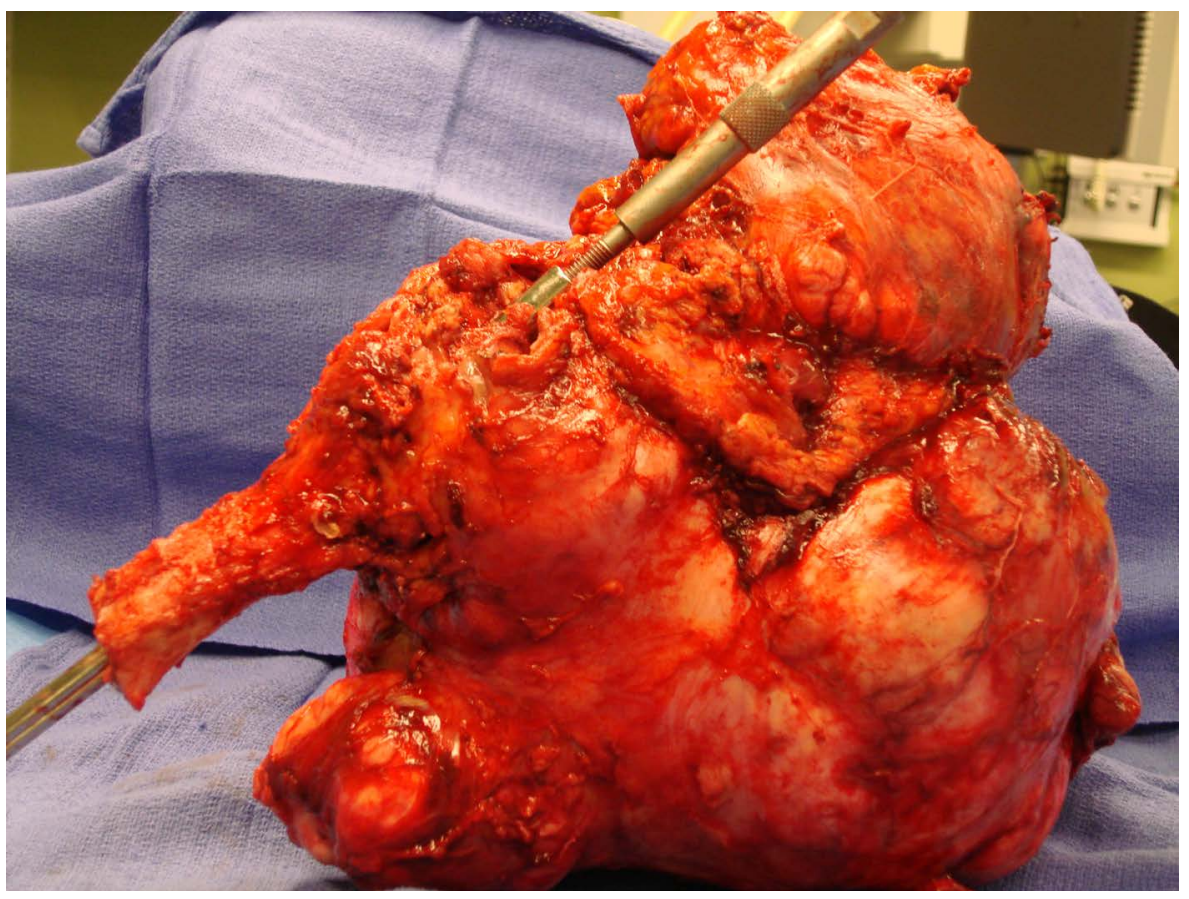

Figure 6. Perioperative aspect of the resected tumor.

which are the glenohumeral arthrodesis, the humeral prosthesis (with or without allograft), reversed prosthesis and massive allografts [5]-[9] [12]-[15].

When proximal humerus and the entire scapula are both invaded, as was the case of our patient, scapula and proximal humerus reconstruction options are limited. Scapular osteoarticular allograft reconstruction after scapular tumors resection are rarely reported and limited. After resection of the entire scapula, the glenohumeral joint or proximal humerus is damaged; the remaining humerus can be suspended from clavicle or ribs. However, the trend has been reconstruction with a scapular prosthesis in order to obtain better functional and cosmetic 


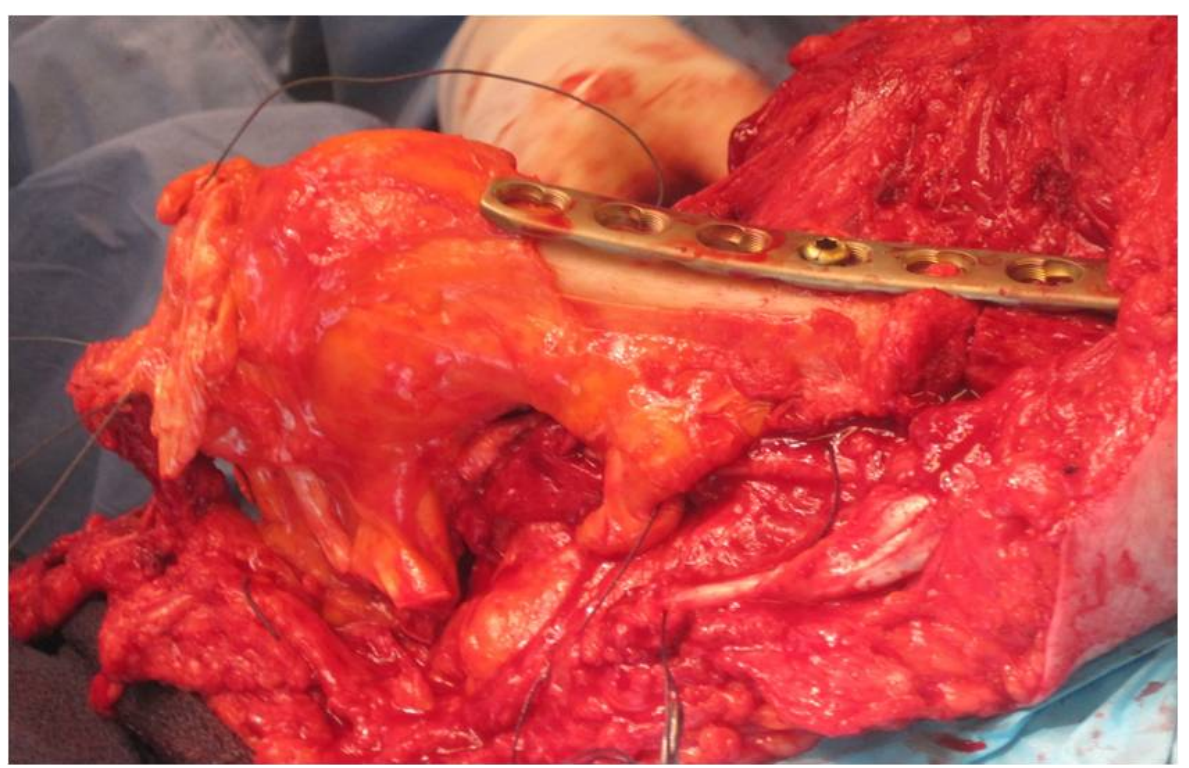

Figure 7. Perioperative aspect of the allograft osteosynthesis with non-invaded distal humerus and fixation of muscular structures to the allograft tendons.

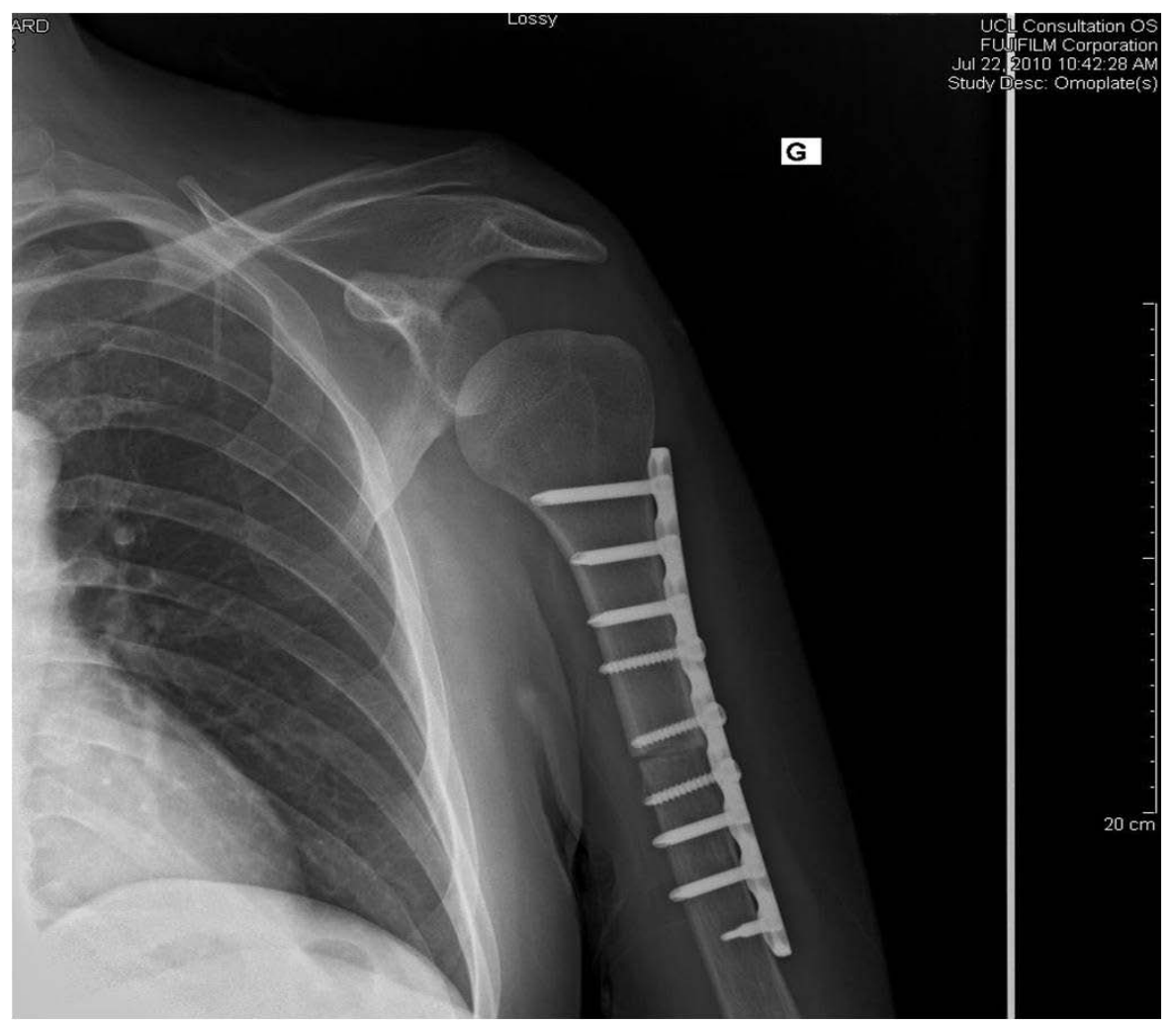

Figure 8. AP postoperative X-ray of the humerus shows the quality of the osteosynthesis.

results. Every method has its advantages and disadvantages so that there is no optimal reconstructive strategy [9] [14] [16]. For the preservation of shoulder function after total scapulectomy, not only soft tissue reconstruction but also bony reconstruction is theoretically preferable. Prosthetic reconstruction is the most common procedure in bone tumor surgery, but the availability of scapular prosthesis is much lower, which directly relates to functional recovery [16]. 


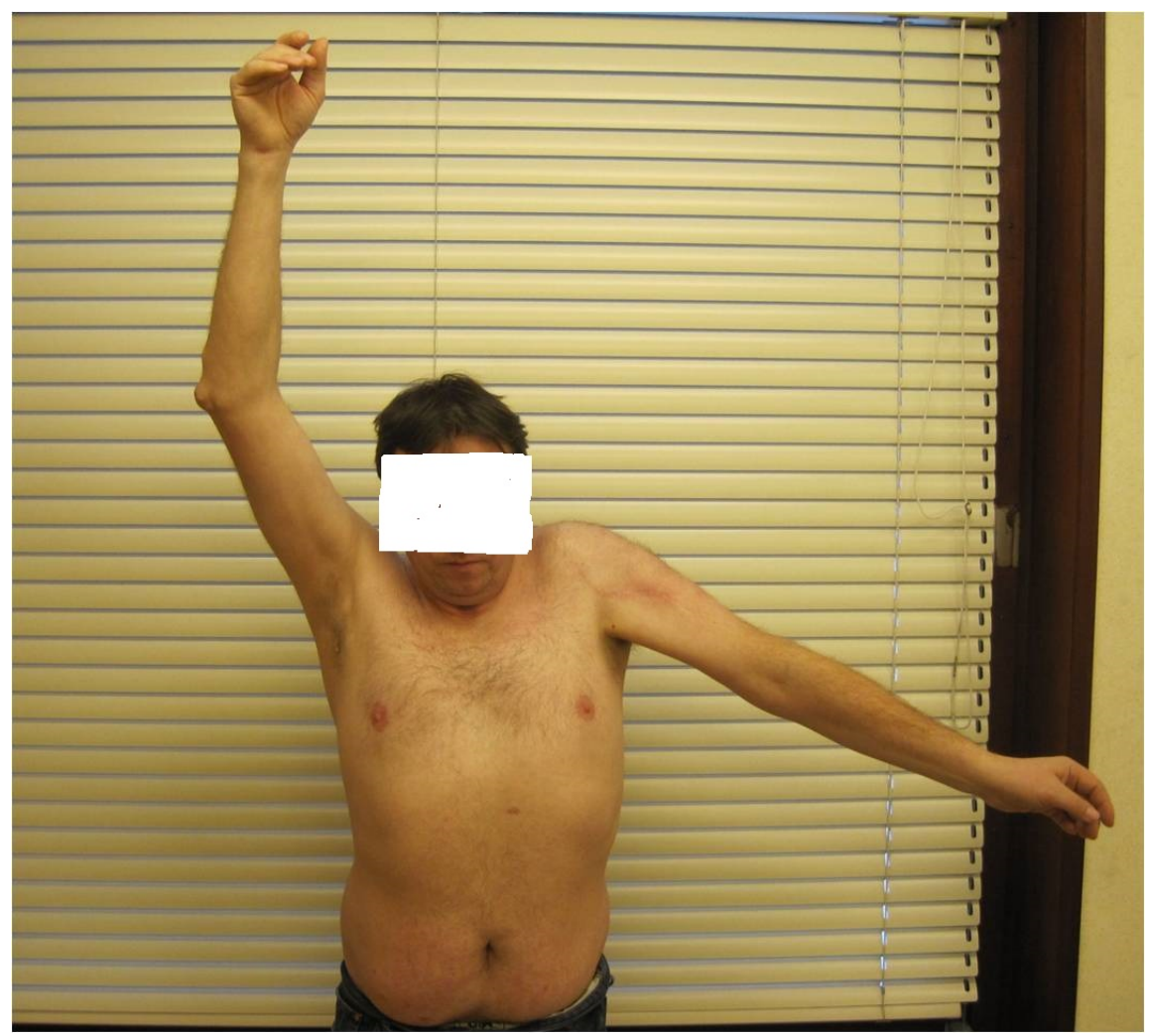

Figure 9. Limited abduction at $30^{\circ}$ of the patient one year after surgery.

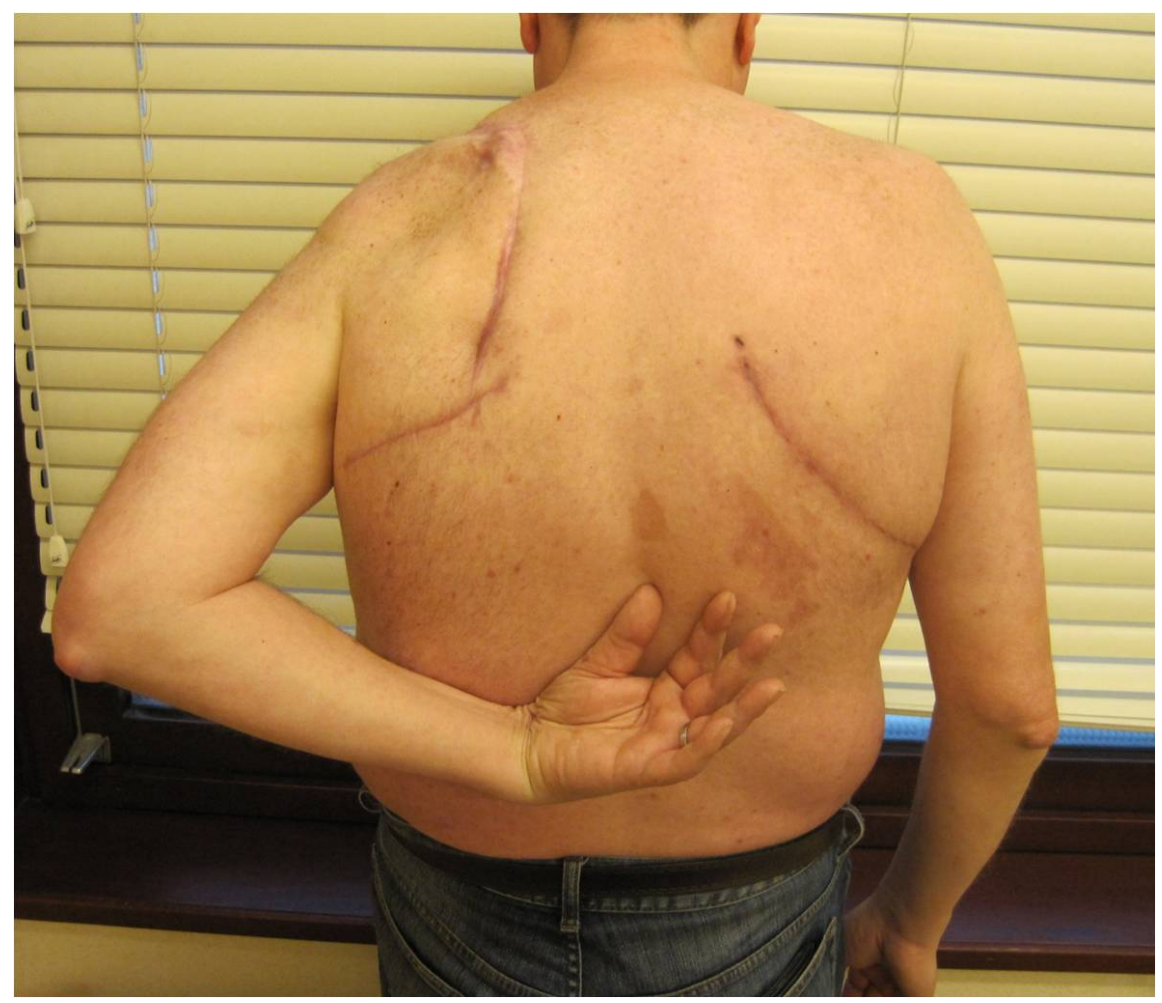

Figure 10. Patient one year after surgery showing an internal rotation at D10. Right, we can see scar for lung nodule resection. 


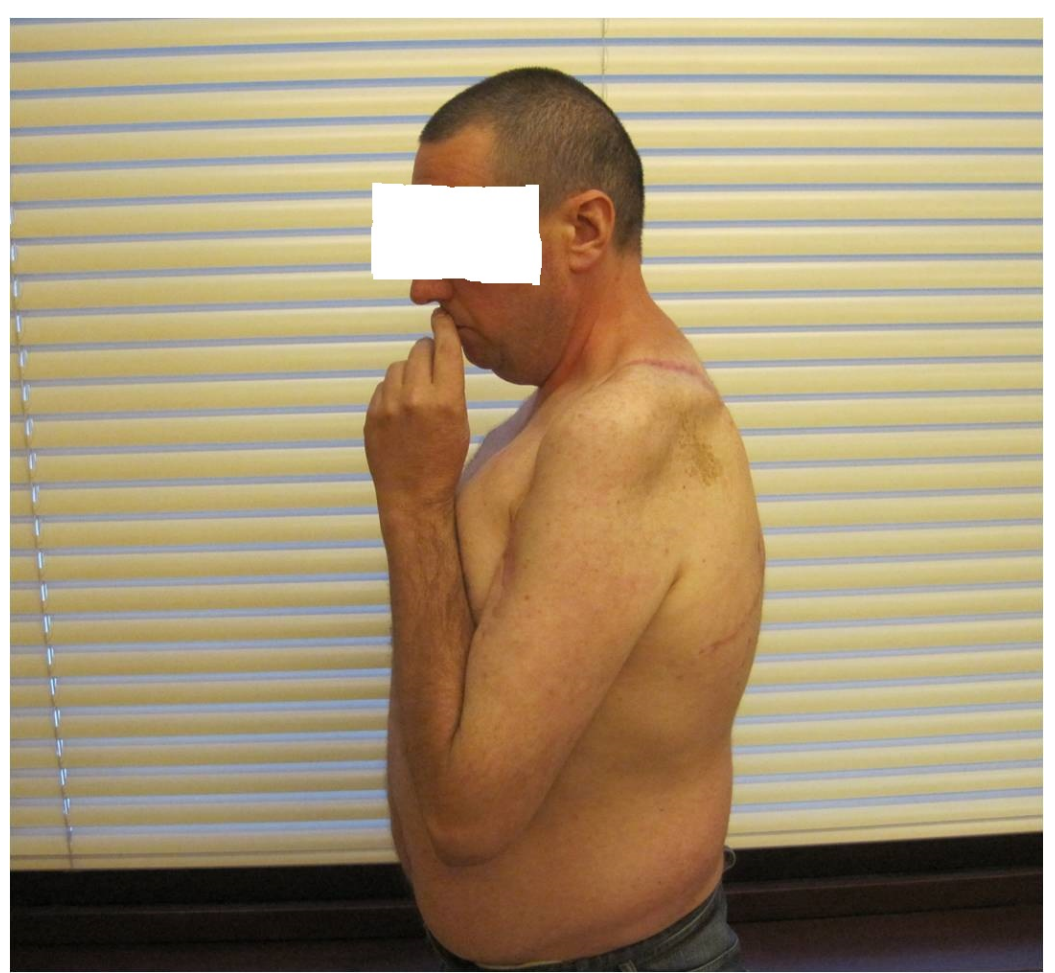

Figure 11. Normal function of the patient hand and elbow one year after surgery.

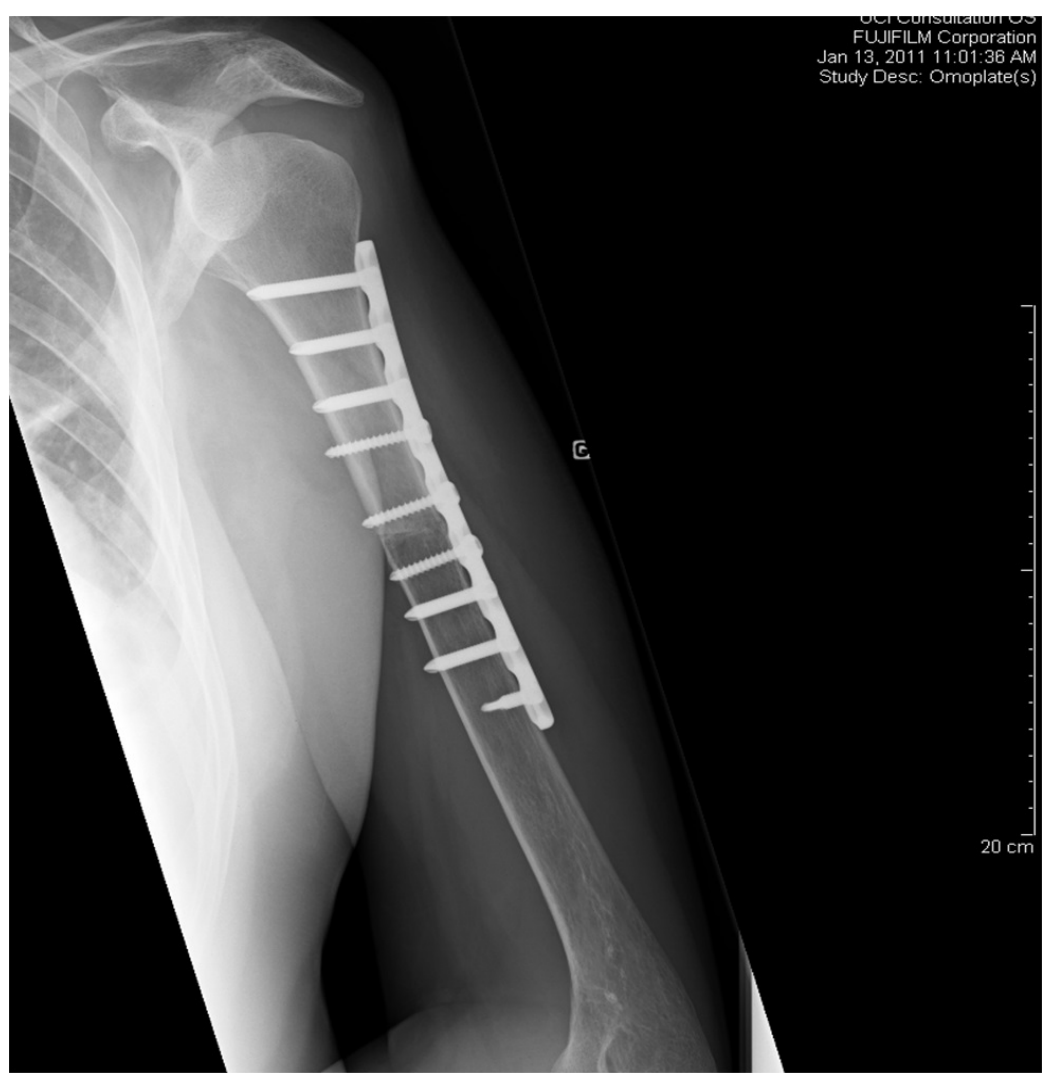

Figure 12. One year control X-ray view of the solidification of allograft distal humerus junction. 
The use of osteoarticular allograft in oncology surgery is well known with good functional outcome [17]. Compared to constrained scapular prosthesis, massive scapular-proximal humerus osteoarticular allograft is a relatively new and rather promising option for the treatment of patients with proximal humerus and the entire scapula are both invaded. However, a number of advantages including, like all osteoarticular allografts, the advantage of being anatomical, theoretically rehabitable, and allow easier tendon reinsertion than on a prosthetic metal surface, greater range of motion and early mobilization. It should also be noted that the risk of dislocation is reduced.

There uses remains attractive, however, there are still limiting factors, such as the necessity of a reliable tissue bank with quality allografts in sufficient number is paramount [17].

On the one hand, they must not overshadow osteocartilaginous resorption and associated fractures. Long term complications include pseudarthrosis and fractures. Before 12 months, they are related to huge fragility due to screw holes. After 12 months, complications are constraint fractures and after 24 months, they are stress fractures. After 48 months, complications are related to massive allograft resorption [18]. On the other hand, complications are infectious, especially in immunosuppressed patients after aggressive chemotherapy. These allografts can be used alone or in combination with either a prosthesis or osteosynthesis as was the case of our patient revision surgery.

Regarding the reconstruction of soft tissue, the deltoid muscle plays the most important role in stability and shoulder function. It was partially sacrificed in our patient. The capsule acts as a joint stabilizer. However, to restore shoulder function and maintain the stability of the shoulder, the rotator cuff, especially the supraspinatus muscle, should also be preserved as much as possible. Careful preparation of the supraspinatus and infraspinatus and their nerve supply are required to obtain a satisfactory outcome of the reconstruction.

The main aim musculoskeletal malignancies resection is tumor remission, and secondly the need to preserve the limb and its function, and aesthetic concerns. The main objective of the reconstruction is to create a functional member which is acceptable to the patient [4] [6] [9] [14].

Our patient continued to develop lung metastases. This could be explained by delays in consultation. Functionally, flexion/extension of the elbow and wrist were normal. The abduction was $30^{\circ}$, internal rotation allows moving the left hand to D10, which is required for most activities of daily living and personal hygiene.

\section{Conclusion}

The reconstruction of the scapula and the proximal humerus by a massive osteoarticular allograft can be an oncologic safety procedure with an acceptable complication rate. Osteoarticular allografts have the advantage of being anatomical, theoretically rehabitable and allow easier tendon reinsertion than on a prosthetic metal surface. They restore bone stock and provide immediate shoulder stability. The necessity of a reliable tissue bank with quality allografts in sufficient number is paramount. Functional and oncological outcomes are related to the timing of consultation period and periarticular structures invasion.

\section{Conflict of Interest}

None.

\section{References}

[1] Dahlin, D.C. (1978) Bone Tumors: General Aspects and Data on 6221 Cases. 3rd Edition, Charles C. Thomas, Springfield, 6-11.

[2] Picci, P. (2014) Epidemiology. In: Picci, P., Manfrini, M., Fabbri, N., Gambarotti, M., Vanel, D., Eds., Atlas of Musculoskeletal Tumors and Tumorlike Lesions, Springer International Publishing, Switzerland, 3-8. http://dx.doi.org/10.1007/978-3-319-01748-8_1

[3] Mnaymneh, W.A., Temple, H.T. and Malinin, T.I. (2002) Allograft Reconstruction after Resection of Malignant Tumors of the Scapula. Clinical Orthopaedic Related and Research, 405, 223-229. http://dx.doi.org/10.1097/00003086-200212000-00029

[4] Nakamura, S., Kusuzaki, K., Murata, H., Takeshita, H., et al. (1999) Clinical Outcome of Total Scapulectomy in 10 Patients with Primary Malignant Bone and Soft-Tissue Tumors. Journal of Surgery Oncology, 72,130-135. http://dx.doi.org/10.1002/(SICI)1096-9098(199911)72:3<130::AID-JSO4>3.0.CO;2-O

[5] Malawer, M.M., Meller, I., Dunham, W.K., et al. (1991) A New Surgical Classification System for Shoulder-Girdle 
Resections. Analysis of 38 Patients. Clinical Orthopaedic Related and Research, 267, 33-44

[6] Burwell, H.N. (1965) Resection of the Shoulder with Humeral Suspension for Sarcoma Involving the Scapula. The Journal of Bone \& Joint Surgery, 47-B, 300-303

[7] Chandrasekar, C.R., Mohammed, R. and Grimer, R.J. (2009) Extracorporeally Irradiated Scapula as Autograft in Tumor Surgery. Journal of Shoulder and Elbow Surgery, 18, 28-32. http://dx.doi.org/10.1016/j.jse.2008.07.014

[8] Ham, S.J., Hoekstra, H.J., Eisma, W.H., Koops, H.S. and Oldhoff, J. (1993) The Tikhoff-Linberg Procedure in the Treatment of Sarcomas of the Shoulder Girdle. Journal of Surgery Oncology, 53, 71-77. http://dx.doi.org/10.1002/jso.2930530204

[9] Lee, F.Y., Hornicek, F.J., Hazan, E.J., Kloen, P., et al. (1998) Reconstruction of the Shoulder Joint Using an Acetabular Allograft. A Report of Two Cases. Clinical Orthopaedic Related and Research, 357, 116-121. http://dx.doi.org/10.1097/00003086-199812000-00015

[10] Schwab, J.H., Athanasian, E.A., Morris, C.D., Boland, P.J., et al. (2006) Function Correlates with Deltoid Preservation in Patients Having Scapular Replacement. Clinical Orthopaedic Related and Research, 452, 225-230. http://dx.doi.org/10.1097/01.blo.0000229323.37793.6d

[11] Richards, R.R., An, K.N., Bigliani, L.U., Friedman, R.J., et al. (1994) A Standardized Method for the Assessment of Shoulder Function. Journal of Shoulder and Elbow Surgery, 3, 347-352. http://dx.doi.org/10.1016/S1058-2746(09)80019-0

[12] Tang, X., Guo, W., Yang, R., Ji, T. and Sun, X. (2011) Reconstruction with Constrained Prosthesis after Total Scapulectomy. Journal of Shoulder and Elbow Surgery, 20, 1163-1169. http://dx.doi.org/10.1016/j.jse.2010.12.014

[13] Vrettos, B.C., Wallace, W.A., Neumann, L. and Frostick, S.P. (2004) Total Scapular Replacement: Medium-Term Follow-Up. Journal of Shoulder and Elbow Surgery, 13, 472-475. http://dx.doi.org/10.1016/j.jse.2004.01.025

[14] Zhang, K., Duan, H., Xiang, Z. and Tu, C.(2009) Surgical Technique and Clinical Results for Scapular Allograft Reconstruction Following Resection of Scapular Tumors. Journal of Experimental \& Clinical Cancer Research, $28,45$. http://dx.doi.org/10.1186/1756-9966-28-45

[15] Wittig, J.C., Bickels, J., Wodajo, F., Kellar-Graney, K.L. and Malawer, M.M. (2002) Constrained Total Scapula Reconstruction after Resection of a High-Grade Sarcoma. Clinical Orthopaedic Related and Research, 397, 143-155. http://dx.doi.org/10.1097/00003086-200204000-00020

[16] Pritsch, T., Bickels, J., Wu, C.C., Squires, M.H., et al. (2007) Is Scapular Endoprosthesis Functionally Superior to Humeral Suspension? Clinical Orthopaedic Related and Research, 456,188-195. http://dx.doi.org/10.1097/01.blo.0000238840.26423.b6

[17] Delloye, C., Brichard, B., Docquier, P.L. and Cornu, C. (2007) Pelvic Reconstruction with a Structural Pelvic Allograft after Resection of a Malignant Bone Tumor. The Journal of Bone \& Joint Surgery, 89-A, 346-354. http://dx.doi.org/10.2106/jbjs.e.00943

[18] Peabody, T.D., Finn, H.A. and Simon, M.A. (1991) Allograft Arthrodesis of the Shoulder after Extra-Articular Resection of Malignant Tumors of the Proximal Humerus. In: Brown, K.L.B., Ed., Complications of Limb Salvage: Prevention Management and Outcome, International Symposium of Limb Salvage, Montréal, 589-592. 